\title{
AS COTAS DE CANDIDATURA POR GÊNERO E A INCONSTITUCIONALIDADE DO PROJETO DE LEI N 1.256/2019.
}

\author{
Raquel Cavalcanti Ramos Machado \\ Jéssica Teles de Almeida ${ }^{2}$
}

\begin{abstract}
Resumo: Diante da alegada ineficácia do $\S 3^{\circ}$ do artigo 10 da Lei $n^{\circ}$ 9.504/97, que tem por objeto as cotas de candidaturas, foi apresentado Projeto de Lei $\mathrm{n}^{\circ} 1.256 / 2019$ para revogação da norma. Investiga-se se a matéria do projeto é constitucional. Conclui-se que não se revoga lei em face de sua mera ineficácia e que a revogação do citado art. 10, $\S 3^{\circ}$ é inconstitucional por violar a igualdade material e por acarretar um verdadeiro retrocesso na promoção do direito à participação política da mulher.
\end{abstract}

Palavras-chaves: Participação política da mulher. Cotas. Ineficácia. Revogação. Inconstitucionalidade.

\section{THE CANDIDATURE QUOTAS BY GENDER AND THE UNCONSTITUTIONALITY OF BILL Nº 1.256/2019.}

\begin{abstract}
In view of the alleged ineffectiveness of paragraph 3 of article 10 of Law $\mathrm{n}^{\circ}$ 9.504 / 97, which has as its object the quotas of applications, Bill $\mathrm{n}^{\circ} 1.256$ / 19 was presented to repeal the rule. It is investigated if the matter of the project is constitutional. It is concluded that the law is not revoked in view of its mere ineffectiveness and that the repeal of said art. 10, paragraph 3 is unconstitutional for violating material equality and for causing a real setback in promoting the right to political participation of women.
\end{abstract}

Keywords: Political participation of women. Quotas. Ineffectiveness. Revocation. Unconstitutionality.

\footnotetext{
1 Professora de Direito Eleitoral da Universidade Federal do Ceará. Advogada. Graduada pela Universidade Federal do Ceará. Mestre pela Universidade Federal do Ceará. Doutora pela USP. Visiting Research Scholar da Wirtschaf UniversistatVienna (2015 e 2016). Professora pesquisadora convidada da Faculdade de Direito da Universidade Paris Descartes (2017). Professora pesquisadora convidada da Faculdade de Direito da Universidade de Firenze (2018). Coordenadora do Grupo de Pesquisa e Extensão em Direito Eleitoral "Ágora: Educação para a cidadania: denúncia e esperança." (UFC). Coordenadorageral do projeto "Observatório Eleitoral do Ceará" (www.observatorioeleitoralce.com). Coautora da Cartilha "A PARTICIPAÇÃO DA MULHER BRASILEIRA NA POLÍTICA".

${ }^{2}$ Professora da Universidade Estadual do Piaui. Coordenadora do Curso de Direito da FIED. Advogada e consultora jurídica. Mestra em Direito pelo Programa de Pós-Graduação em Direito da Universidade Federal do Ceará (UFC). Especialista em Direito Público com Ênfase em Gestão Pública. Graduada em Direito pela Universidade Federal do Ceará (UFC). Pesquisadora do grupo de pesquisa e extensão em Direito Eleitoral "Ágora: Educação para a cidadania: denúncia e esperança" (UFC) e do grupo "Direito Humanos e das Minorias" (UFC). Coordenadora-geral do projeto "Observatório Eleitoral do Ceará" (www.observatorioeleitoralce.com). Coautora da Cartilha "A PARTICIPAÇÃO DA MULHER BRASILEIRA NA POLÍTICA".
} 


\section{INTRODUÇÃO}

O estudo da participação política da mulher é objeto de análise por várias disciplinas, mas vem sendo abordado, nos últimos anos, como muito mais atenção e rigor pelos estudiosos de Direito Eleitoral. A ciência do Direito Eleitoral assume, portanto, grande relevância no estudo e na identificação de problemas que podem ser solucionados com propostas normativas mais protetivas ao bem jurídico em discussão.

No âmbito do direito internacional, desde a década de 50, a desigualdade entre os sexos na ocupação de cargos públicos vem se mostrando como motivo de preocupação estatal, como se pode observar dos normativos presentes na Convenção sobre os Direitos Políticos da Mulher (1953) e na Convenção para Eliminação de Todas as Formas de Discriminação contra a Mulher (1979).

A ONU-Mulheres, em 2014, lançou o Marco Normativo da Democracia Paritária (ONU-MULHRES, 2018), traduzido para o português em 2018, o qual estipula, em seu art. 18, que a paridade na representação política seria alcançada, tanto em sistemas eleitorais de lista aberta e de lista fechada, mediante o recrutamento, em alternância, de homens e mulheres mais votados (segundo as regras de cada sistema eleitoral) para ocupar as vagas no Parlamento.

O Brasil iniciou o processo, a discussão e a deliberação política e jurídica a respeito dessa temática a partir da década de 80, mas foi na década de 90 que se pode constatar, já à luz das novas diretrizes constitucionais, um certo avanço no trato da matéria (MARTINS, 2007).

Notou-se, no decorrer dos anos, ter a legislação eleitoral evoluído na tentativa de fortalecer os mecanismos de inclusão, tendo, em 1997, sido promulgada a Lei $\mathrm{n}^{\circ}$ 9.504/97 (Lei Geral das Eleições) que instituiu as cotas de candidatura para todos os cargos eletivos pelo sistema proporcional e aumentou, ainda, o percentual, que até então era de 20\%, para 30\%. Já a Lei $n^{\circ}$ 12.034/2009 reforçou a proteção jurídica da participação política da mulher ao alterar o texto do art. $10, \S 3^{\circ}$ da Lei $n^{\circ}$ 9.504/97, estabelecendo a obrigatoriedade de cada partido ou coligação preencher o mínimo de 
$30 \%$ (trinta por cento) e o máximo de $70 \%$ (setenta por cento) para candidaturas de cada sexo. Outras medidas foram adotadas, em 2018, pela jurisprudência do Supremo Tribunal Federal (2018) e do Tribunal Superior Eleitoral para garantir mais igualdade participativa às mulheres (FUNDO..., online, 2018) ${ }^{3}$.

Após as eleições de 2018, as mulheres passaram a ocupar 15\% (TRIBUNAL SUPERIOR ELEITORAL, online, 2018) dos espaços formais de poder. Houve, assim, um incremento, apesar de diminuto, no número de mulheres eleitas em 2018. O Congresso Nacional possui, atualmente, 77 (setenta e sete) deputadas federais e 12 (doze) senadoras. Segundo o ranking elaborado pela União Interparlamentar (IPU), o Brasil ocupa a $156^{\mathrm{a}}$ posição, em uma lista de 190 países, que mede a participação feminina na política (MONTESANTI, online, 2018).

$\mathrm{O}$ aumento de $5 \%$ nesse percentual pode ser atribuído aos incentivos jurídicos aplicáveis às eleições de 2018, como a reserva de recurso para campanha das candidatas, inobstante as denúncias de fraudes dos repasses, pelos partidos políticos, das verbas, às candidatas que muitas vezes são verdadeiras "laranjas" (ALMEIDA;MACHADO, online, 2018b);(O AMARGO..., online, 2018); (JUVÊNCIO, 2013).

A tendência contemporânea segue sendo a realização de reformas legislativas com a finalidade de alcançar mais equidade de gênero na política (LAFUENTE, online, 2014); (ARGENTINA..., online, 2017). As medidas atuais adotadas colocam as mulheres, de fato, em "posição competitiva na lista partidária" (HTUN, 2001).

As cotas de gênero ${ }^{4}$ são uma realidade normativa em vários outros países europeus e em várias instâncias de participação política democrática (SOUZA, 2011).

\footnotetext{
${ }^{3}$ Considerando o real contexto de baixa representatividade feminina no cenário da política nacional, o Supremo Tribunal Federal, mediante a ADI $\mathrm{n}^{\circ}$ 5617, e o Tribunal Superior Eleitoral, na Consulta $\mathrm{n}^{\circ}$ 0600252-18.2018.6.00.0000, no ano de 2018, ao serem instados a estabelecer a interpretação da legislação eleitoral a respeito do financiamento de campanha, fixaram interpretações no sentido de garantir que, pelo menos 30\% dos recursos do Fundo Partidário e do Fundo Especial de Financiamento de Campanha, fossem reservados às candidaturas femininas. A referidas decisões, verdadeiras fontes de Direito, incluíram no ordenamento jurídico brasileiro, uma nova ação afirmativa voltada ao fomente e proteção da participação política da mulher.

${ }^{4}$ Após a decisão do TSE, em 01 de março de 2018, nos autos da Consulta no 0604054-58.2017.6.00.0000, em que a Corte foi instada a se manifestar sobre a participação política das pessoas trans, ficou decidido que as cotas não de gênero e não de sexo. Com base nos estudos de Judith Butler (2003): "Nesse ponto, importa fazer a distinção entre sexo e gênero, já que como se percebe, a legislação, inúmeras vezes usa $o$ Rev. de Teorias da Democracia e Direitos Políticos | e-ISSN: 2525-9660 | Goiânia| v. 5 | n. 1 | p. 82-103| 
Percebe-se, assim, terem as reformas legislativas realizadas nos países citados concedido mais chances e espaços às mulheres desenvolverem suas campanhas independente da vontade partidária, a qual pode não as favorecer.

Como anotam Dias e Quintela (2016), as medidas afirmativas devem estabelecer "certas vantagens compensatórias da discriminação e exclusão estruturais impostos historicamente às mulheres".

A participação política tem a natureza de jurídica de direito fundamental (LOPES, 2011) e de direito humano por também se encontrar prevista em documentos internacionais ${ }^{5}$. As cotas são a principal medida de inclusão adotada para fomentar e proteger esse bem jurídico (BRASIL, 2015, p. 12). No norte da Europa, essa ferramenta começou a ser adotada ainda na década de 70 (BIROLLI; MIGUEL, 2014) e foi se estendendo a outras regiões, sendo, atualmente, uma constante em várias legislações de países europeus (SOUZA, 2011).

Contudo, na contramão dessa tendência contemporânea de fortalecimento da proteção jurídica da participação política das mulheres, as cotas de candidaturas estão sendo alvo de inúmeras reflexões positivas - no sentido de aperfeiçoá-las e protegê-las das fraudes (ALMEIDA, 2018) -, mas também negativas - no sentido de extingui-las.

O deputado Ângelo Coronel (PSD-BA) apresentou o Projeto de Lei $n^{\circ}$ $1.256 / 2019$ que tem por objeto a revogação das cotas de candidaturas previstas no parágrafo $3^{\circ}$ do artigo 10 da Lei $n^{\circ}$ 9.504/97, também conhecida com Lei Geral das Eleições. A justificativa seriam as inúmeras denúncias a respeito de fraudes e a suposta ineficácia das cotas. O referido projeto já entrou em processo de discussão e teve voto contrário do relator, Senador Fabiano Contarato (Rede-ES) (PROJETO..., online, 2019).

Diante da problemática que está proposta para discussão atualmente no Congresso Nacional, a respeito da manutenção ou revogação das chamadas "cotas de gênero", também conhecidas popularmente como "cotas para mulheres na política", este trabalho visa auxiliar os estudos jurídicos e debates legislativos a respeito do tema.

$\mathrm{O}$ artigo estrutura-se em três capítulos. O primeiro capítulo se dedicará a fazer uma análise das cotas de gênero na política e no ordenamento jurídico brasileiro.

termo sexo e não gênero. Sexo está relacionado a aspectos biológicos do corpo, já o gênero é "culturalmente construído" e corresponde a "significados culturais assumidos pelo corpo".

${ }^{5}$ Como na Convenção Para Eliminar Todas as Formas de Discriminação Contra a Mulher - CEDAW (1979) e na Convenção sobre os Direitos Políticos da Mulher (1953). 
O segundo apresentará a responsabilidade dos partidos na promoção da participação política da mulher e em que medida eles são os responsáveis pela parcial ineficiência das cotas e o terceiro, por fim, apresentará as razões jurídicas para inconstitucionalidade do Projeto de Lei $\mathrm{n}^{\circ}$ 1.256/2019. O método utilizado foi o documental e bibliográfico, com buscas nos sítios eletrônicos do Tribunal Superior Eleitoral e Tribunal Regional Eleitoral do Ceará e também por meio de pesquisas em textos e livros que remetem ao tema do processo eleitoral.

\section{AS COTAS DE CANDIDATURA}

O presente capítulo abordará, a partir de um panorama mais geral, a origem das cotas, sua previsão no ordenamento jurídico, assim como os países que a adotam e adotaram, a fim de contextualizarmos melhor a proposta da "política de cotas".

\subsection{Origem das Cotas}

A "política de cotas" começou a ser adotada no final de 1970 em países integrantes do norte da Europa e baseia-se, num primeiro momento, em uma questão de justiça intuitiva, vez que é uma política que busca a proteção de um grupo/categoria que perfaz mais de metade da população e do eleitorado (BIROLLI; MIGUEL, 2014). O déficit histórico de exclusão é uma das primeiras e mais evidentes causas apresentadas pela literatura para explicar essa renitente sub-representação da mulher na política (ARAÚJO, 2001).

No contexto latino-americano, o primeiro país a instituir cotas para mulheres na esfera Parlamentar foi a Argentina, em 1991, cuja legislação inspirou e ainda inspira outros países vizinhos na adoção desse mecanismo diante da efetividade do seu modelo na reversão do seu grave quadro de sub-representatividade feminina na política (HTUN, 2001).

\subsection{As cotas de candidatura no Brasil}


O texto legal do art. $10, \S 3^{\circ}$ da Lei $n^{\circ}$ 9.504/97 garante, no processo eleitoral, que as candidaturas obedeçam uma proporção mínima para cada gênero, o que concretiza o princípio da igualdade material (MACHADO, 2018). A justificativa é que essa medida garantirá a diversidade nas candidaturas lançadas e não haveria o risco de um gênero se sobrepor ao outro. Ou seja, se algum dia as mulheres passassem a ser a maioria dos postulantes a candidaturas, a norma assegurará, no futuro, de igual maneira, um mínimo de vagas para os homens, protegendo também sua participação política.

Logo, a justiça da medida estaria em garantir espaços de participação minimamente paritária para ambos os gêneros, numa proporção que não atrapalharia a livre concorrência que rege o processo eleitoral, o qual se funda na liberdade de voto do eleitor e em um amplo debate e apresentação de ideias e propostas para captação, pelos candidatos, de preferências políticas, em um mínimo patamar de igualdade uns com outros.

$\mathrm{O}$ ar. $10, \S 3^{\circ}$ da Lei Geral das Eleições busca tornar o processo eleitoral mais justo, trazendo mais igualdade de oportunidades às mulheres. $\mathrm{O}$ mito da simples meritocracia já vem sendo derrubado há muito tempo e estudos desenvolvidos no âmbito da filosofia constitucional, por autores como John Rawls (2000), Walzer (2003) e Ronald Dworkin (2010; 2016), há muito já vêm denunciando que uma competição justa, em que todos possam ter as mesmas oportunidades, dependem de todos se acharem, incialmente, na posição e com as mesmas chances, o que não existe numa sociedade complexa e diferenciada como a nossa, marcada por ciclos e históricos de exclusão de grupos em detrimento do amplo acesso de outros. A igualdade de oportunidade é um dos valores caros às competições eleitorais (SÁNCHEZ MUÑOZ, 2007).

Rawls, em sua proposta para uma teoria da justiça, alertava que "as instituições da sociedade favorecem certos pontos de partida mais que os outros" (RAWLS, 2000, p.8). Para o autor as desigualdades são "socialmente profundas. Não apenas são difusas, mas afetam desde o início as possibilidades de vida dos seres humanos; contudo, não podem ser justificadas mediante um apelo às noções de mérito ou valor" (RAWLS, 2000, p.8). Diante das ponderações de Rawls, indaga-se: Será que os homens alcançam $85 \%$ dos cargos político-eletivos por mérito próprio ou existe uma infraestrutura política e eleitoral que os favorece? 
Beauvoir (2000, p. 14-15) com muita lucidez e coragem, há mais de 50 anos, já revelava em suas pesquisas que os dois sexos nunca compartilharam o mundo de forma igualitária e que, mesmo em iguais condições, os homens sempre tem posições mais vantajosas. Ou seja, mesmo diante das mesmas condições formais de acessarem o mercado de trabalho e a política, eles possuem os salários mais altos, ocupam os postos mais importantes e estão em maior número na política, pois eles gozam de "um prestígio cuja tradição a educação da criança mantém".

As cotas de candidatura são, portanto, ações afirmativas que visam reparar padrões históricos de desigualdades (LOPES, 2011). As ações afirmativas são mecanismos pensados para se concretizar o princípio da igualdade material (SARMENTO, 2011).

\subsection{Países que adotam as cotas de candidatura}

Na América Latina, não só o Brasil adota cotas que visam incluir mais mulheres na política. Conforme se pode observar do quadro abaixo, extraído da Revista do Observatório Brasil da Igualdade de Gênero, em 2015, os países que introduziram essas medidas em seu ordenamento jurídico são os seguintes:

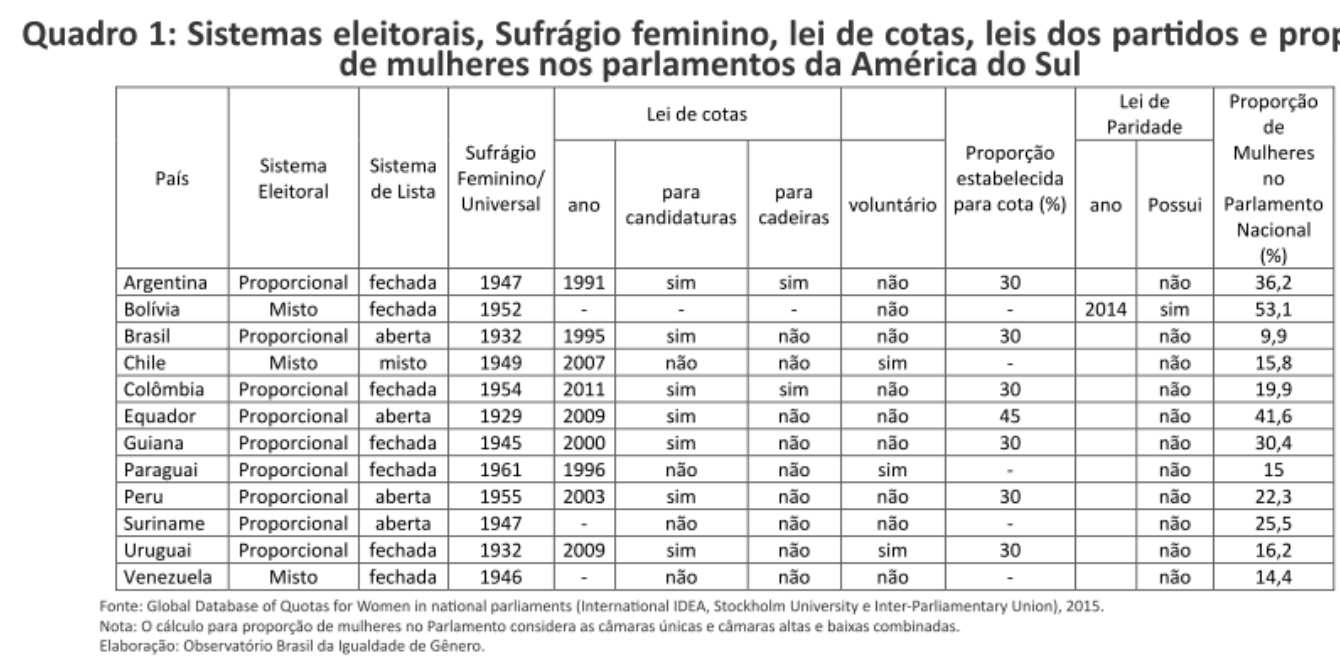

Fonte: Global Database of Quotas for Women in national parliaments (International IDEA, Stockholm University e Inter-Parliamentary Union), 2015.

Nota: O cálculo para proporção de mulheres no Parlamento considera as câmaras únicas e câmaras altas e baixas combinadas.

Elaboração: Observatório Brasil da Igualdade de Gênero (BRASIL, 2015, p. 12) 
As cotas também são adotadas em países europeus, como bem esclarece Souza (2011).

\section{$2.4 O$ sucesso das cotas de candidaturas no exterior}

Apesar de o Brasil ainda não ter conseguido alcançar índices mais satisfatórios em termos de igualdade de gênero na política, há países, como a Argentina e a Bolívia, por exemplo, que, após a implantação das cotas (e de uma séria de leis reforçando-as), aliada ao sistema político do país, passaram a contar com mais mulheres em postos de poder.

A Argentina, país pioneiro na adoção de cotas na política na América Latina, que já havia alcançado, com as cotas de candidatura de 30\%, em lista fechada, uma inclusão considerável de mulheres na política, adotou, em 2017, a Lei de Paridade. A partir de 2019, na Argentina cada partido apresentará 50\% de candidatas mulheres (ARGENTINA..., online, 2017).

Em Portugal, apesar de na década de 90 ter havido uma tentativa de adoção legislativa de cotas em 1998/1999 (SANTOS, SANTO, 2017), foi apenas em 2006, após a promulgação da Lei de Paridade Portuguesa (Lei Orgânica no 3/2006), que o direito à participação política da mulher passou a contar com uma proteção legislativa significativa (MONTEIRO, 2011, p. 31). A referida lei garante a presença de, no mínimo 33\%, para cada sexo nas listas eleitorais para a Assembleia da República, para o Parlamento Europeu e para as autarquias locais.

Para Monteiro (MONTEIRO, 2011, p. 31), a Lei de Paridade Portuguesa é um "marco importantíssimo na promoção da igualdade de mulheres e homens". Ela instituiu as cotas de mulheres na política e foi fruto de mais de 30 (trinta) anos de reinvindicações.

A Revista Observatório Brasil de Igualdade de Gênero de 2015 indica que, com exceção do Brasil, os países que adotaram a "lei de cotas" têm parlamentos mais equânimes em termos de representação por sexo (BRASIL, 2015), apontando ainda que quando a Venezuela instituiu a lei de cotas em 1998 a representação feminina aumentou de $6 \%$ para $12 \%$ e que, após ser extinta tal lei, esse percentual caiu para 9,7\% (BRASIL, 2015, p. 14).

Rev. de Teorias da Democracia e Direitos Políticos | e-ISSN: 2525-9660 | Goiânia| v. 5 | n. 1 | p. 82-103| 
Não se desconhece que são vários os fatores envolvidos nesse processo de inclusão, até por que, como alerta Araújo (2001, p. 232) existe toda uma "lógica político-pragmática envolvida nas empreitadas em torno do poder".

Destaca ainda Araújo (2001, p. 232) que países da América Latina que possuem "trajetórias e culturas políticas semelhantes às do Brasil, e talvez mais conservadores quanto ao chamado 'machismo latino', vêm apresentando quadros bem mais favoráveis às mulheres na esfera política, inclusive em relação às suas iniciativas de cotas", tendo sido a adoção delas um dos fatores cruciais, como foi no caso da Argentina e Bolívia, para se alcançar mais igualdade de gênero na política.

Apesar das diferenças entre o papel dos partidos políticos nesses países, tanto o modelo adotado pela Argentina, como adotado pela Bolívia, colocam as mulheres em condições de competividade que supera as questões partidárias, ou seja, impedindo que os partidos políticos fraudem a medida (ARAÚJO, 2010). Eis o ponto o central. Os modelos que obtém êxito possuem normas que colocam as mulheres em “posição competitiva na lista partidária” (HTUN, 2001).

\section{PARTIDOS POLÍTICOS E SUA OBRIGAÇÃO LEGAL DE FORMAREM A CAPACITAREM MULHERES PARA A POLÍTICA FORMAL}

As cotas de candidatura tratam-se de uma política de Estado. A Constituição de 1988 também prevê a igualdade entre homens e mulheres e a adoção de medidas para eliminação de desigualdades entre os sexos.

A prática política nos revela que o acesso do poder político está restrito ainda a certos grupos de modo que aquele almejante a disputar esses espaços enfrentará muitos obstáculos. Esses obstáculos advêm principalmente de uma situação de desigualdade presente nas estruturas sociais que acabam minando para as esferas políticas.

As cotas de candidaturas desenvolvem um papel importantíssimo no processo eleitoral, pois viabilizam que um grupo sub-representado (mulheres) exercite, com mais amplitude, seu direito à participação política ao se destinar uma reserva de espaço para que possam apresentar suas ideias, visões de mundo, suas identidades,

Rev. de Teorias da Democracia e Direitos Políticos | e-ISSN: 2525-9660 | Goiânia| v. 5 | n. 1 | p. 82-103| 
contribuindo para a "democratização" desse "mercado político" e do processo de formação, pelo eleitor, da sua convicção político-eleitoral.

Para que as cotas de candidatura cumpram sua função é preciso que as candidaturas lançadas pelos partidos sejam viáveis. Não basta que o partido lance $30 \%$ de candidaturas femininas apenas para obedecer um critério formal, é necessário que essas candidaturas se desenvolvam ou, ao menos, tenham potencial para se desenvolverem.

Para dar efetividade à política de cotas, a Lei n ${ }^{\circ}$ 9.096/95, (Lei dos Partidos Políticos) passou a prever, em seu art. 44, caput, inciso $\mathrm{V}$ e $\S 5^{\circ}$ e $\S 7^{\circ}$, que as agremiações partidárias mantenham programas de promoção e difusão da participação política das mulheres, através da Secretaria da Mulher do respectivo partido político ou, na ausência desta, mediante o Instituto ou Fundação de Pesquisa e de Doutrinação e educação política. A instituição da fundação é obrigação legal dos partidos, tanto que $20 \%$ das verbas do Fundo Partidário são de uso vinculado a esse fim (art. 44, IV da Lei $\left.n^{\circ} 9.096 / 95\right)$.

Já o art. $9^{\circ}$ da Lei $n^{\circ}$ 13.165/15 instituiu a Reserva de Fundo Partidário para o financiamento de campanhas de mulheres, tendo o Supremo Tribunal Federal, nos autos da ADI n 5617 , determinado que 30\%, no mínimo, dos recursos do Fundo Partidário destinados a financiamento eleitoral, devem ser usados para custear candidaturas femininas.

\subsection{Será que faltam mulheres interessadas por políticas? $O$ que os partidos omitem nesse debate.}

Acontece que os partidos vêm reiteradamente descumprindo as determinações legais ${ }^{6}$ e sendo os protagonistas, eleições após eleições, de fraudes, ou seja, de práticas ilícitas, contra a política de cotas. Os principais argumentos das agremiações seriam que (1) as mulheres não se interessariam por política e (2) faltam mulheres para preencherem as cotas de candidaturas.

${ }^{6}$ Essa conclusão foi extraída da análise dos seguintes precedentes: Prestação de Contas $\mathrm{n}^{\circ}$ 71468.2011.6.00.0000, Prestação de Contas $\mathrm{n}^{\circ}$ 971-30.2010.6.00.0000, Prestação de Contas $\mathrm{n}^{\circ}$ 23167.2013.6.00.0000, Prestação de Contas $n^{\circ}$ 773-56.2011.6.00.0000, Prestação de Contas $\mathrm{n}^{\circ}$ 87748.2011.6.00.0000, Agr-Prestação de Contas n ${ }^{\circ}$ 202-17-2013.6.00.0000, Prestação de Contas $n^{\circ}$ 26661.2012.6.00.0000.

Rev. de Teorias da Democracia e Direitos Políticos | e-ISSN: 2525-9660 | Goiânia| v. 5 | n. 1 | p. 82-103| 
O primeiro argumento é falso. Como comprova Lúcia Avelar (2007), as mulheres são a minoria na política formal, mas são a maioria na política informal, ou seja, naquela política que se faz na sociedade ou na comunidade, através dos movimentos sociais e protestos. Isso ocorre porque, enquanto nos movimentos sociais a lógica é a inclusão (quanto mais forças agregadas, mais forte e legítimo é o movimento), nos partidos e nos centros de poder instituídos a lógica é da exclusão para minimizar as disputas (AVELAR, 2007).

O segundo argumento também é falso. Os partidos descumprem as normas dos arts. 44, caput, inciso $\mathrm{V}$ e $\$ 5^{\circ}$ e $\$ 7^{\circ}$ (segundo a interpretação conforme dado pelo STF na ADI no 5617), da Lei no 9.096/95 e, por isso, nas vésperas do período eleitoral não se consegue ter acesso às mulheres com capital e interesse político no pleito.

\subsection{Os partidos políticos, fraudes e as "candidaturas laranjas}

Percebe-se, assim, um ciclo omissivo e ilegal partidário. Ao deixarem de investir na busca e capacitação de mulheres para se inserirem nos seus quadros, como determina a legislação, os partidos, às vésperas das eleições fraudam as cotas de candidaturas lançando candidaturas "laranjas". Defendem-se das fraudes alegando que não existem mulheres interessadas em se candidatar, mas omitem que deveriam, pois se insere na sua missão institucional, formar e capacitar mulheres para tanto.

Nota-se, assim, que ao lançar essas candidaturas "laranjas", os partidos claramente se desviam da sua função social e passam a abusar do seu direito de postular e lançar as candidaturas eleitorais, residindo, aí, claramente, o abuso de poder partidário. Quem atenta contras as cotas e contra a lei são as agremiações partidárias (AVELAR, 2007); (ALMEIDA;MACHADO, 2018a).

\subsection{Fraudes e a necessária punição dos infratores}

Assim como o poder político se distingue dos outros poderes sociais, o Direito se distingue das outras ordens sociais na medida em que, sendo produto daquele, pode se valer da coação (força), em caso de resistência, para impor sanção a quem descumpre as suas normas (KELSEN; 1998).

Rev. de Teorias da Democracia e Direitos Políticos | e-ISSN: 2525-9660 | Goiânia | v. 5 | n. 1 | p. 82-103| 
A prática de fraudes às cotas de candidatura envolvendo partidos políticos e muitas mulheres - deve desencadear um reforço e uma proteção maior da medida jurídica e não sua exclusão. O Direito estipula as normas e também um conjunto de sanções para que suas normas possam se fazer cumprir. O Tribunal Superior Eleitoral, por exemplo, avançou nesse ponto ao passar permitir que as fraudes às cotas possam ser objeto de ações eleitorais que podem levar à perda do mandato e até mesmo à constituição de inelegibilidades (ALMEIDA; MACHADO, 2018a). Todos podem fiscalizar o cumprimento da cotas. Aliás, é da essência da democracia uma fiscalização constante dos atos eleitorais e de governo (SHAPIRO, 2006).

A investigação e a punição dos inúmeros casos e escândalos de fraudes constatados nas eleições de 2018 devem ser apurados com rigor por todos os atores do processo eleitoral, em especial a Justiça Eleitoral e o Ministério Público Eleitoral.

\section{A INCONSTITUCIONALIDADE DO PROJETO DE LEI N.o 1.256/2019: PROIBIÇÃO DO RETROCESSO POLÍTICO E DEMOCRÁTICO}

Segundo Scott (2005, p. 29) "A política tem sido descrita como a arte do possível; eu preferiria chamá-la de negociação do impossível". Para a autora, a política é "a tentativa de chegar a soluções que - em sociedades democráticas - aproximam os princípios da justiça e da igualdade, mas que só pode sempre falhar". Essa falha é que abre à política a novos arranjos, como se vem notando com a evolução - e não com a involução - da proteção jurídica da mulher na política.

Os debates em torno das medidas jurídicas para fomentar a participação política da mulher inserem-se nesse contexto de busca por novos arranjos que visem aproximar o processo eleitoral brasileiro dos princípios da justiça e da igualdade material. E, na contramão da tendência contemporânea, depara-se no Brasil com o contrário, qual seja, com iniciativas para a extinção das cotas de candidatura por gênero. A participação política da mulher, no Brasil, parece ser tema da órbita da "negociação do impossível”.

Os resultados eleitorais de 2018 (TRIBUNAL SUPERIOR ELEITORAL, online, 2018); (MONTESANTI, online, 2018); (ASSIS; FERRARI, LEÃO, online, 2018), ao nosso ver, confirmam a importância da política de inclusão que vem sendo 
desenvolvida desde 1995 e aprimorada a cada processo eleitoral. Esse quadro empírico reforça, ainda mais a inconstitucionalidade do Projeto de Lei $n^{\circ}$ 1.256/2019.

Não se pode admitir o retrocesso de um direito tão importante (participação política da mulher) e da reserva de espaços tão necessários (cotas) para a consolidação da democracia. Uma grande parcela da população adulta não está plenamente inserida na política e no processo de tomada de decisões de interesse de todos e todas, o que, para Dahl (2012) é um indicativo de grave deficiência democrática.

Diante da importância política e jurídica do tema, discute-se neste tópico se uma (1) lei pode ser revogada meramente por sua parcial ineficácia e (2) e se essa revogação é constitucional.

\subsection{A inconstitucionalidade do Projeto de Lei $n^{\circ} 1.256 / 2019$}

Pela problemática apresentada na introdução, não existem dúvidas de que a proteção da participação política da mulher é um valor atual. A tendência legislativa contemporânea é no sentido de aumentar a proteção jurídica desse bem.

Contudo, as fraudes às cotas de gênero praticadas pelos partidos políticos, além de afetarem a normalidade e a legitimidade das eleições através da prática de abuso de poder político partidário, acenam que o problema não está no Direito ou, mais precisamente, na legislação eleitoral que certamente tem seu poder simbólico (NEVES, 1994), mas sim em alguns autores do processo eleitoral, como candidatos e partidos políticos.

O Direito convive com a possibilidade de ineficácia de suas normas; aliás o Direito só existe por não poder se esperar o cumprimento voluntário das normas que regem uma comunidade social. A força cogente do ordenamento jurídico estatal é uma das principais ferramentas do Direito (KELSEN, 1998).

O modelo legislativo de proteção à participação política da mulher vigente já reflete um certo avanço nessa corrida por igualdade de gênero na política, pois, sem dúvida, acena que o Estado brasileiro reconhece o seu dever na concretização dos pactos internacionais ratificados e da Constituição Federal (art. $\left.5^{\circ}, \mathrm{I}\right)$.

O primeiro sintoma da inconstitucionalidade do projeto está na sua apresentação contingencial. A participação política das mulheres e sua proteção jurídica, mais especificamente as fraudes às cotas de candidaturas femininas nas eleições de Rev. de Teorias da Democracia e Direitos Políticos | e-ISSN: 2525-9660 | Goiânia| v. 5 | n. 1 | p. 82-103| Jan/Jun. 2019 
2018, foram um dos assuntos mais comentados no meio político brasileiro, principalmente por terem desencadeado uma crise de governo após ter sido amplamente noticiado que o partido do atual Presidente da República, o Partido Social Liberal (PSL), esteve no centro de uma dessas práticas fraudulentas. Instaurada essa crise governamental, não demorou a iniciar questionamentos a respeito da própria legitimidade da medida, tanto que o deputado Ângelo Coronel (PSD-BA) apresentou o Projeto de Lei $n^{\circ} 1.256 / 2019$.

O citado projeto, que tem por objeto a revogação das cotas de candidaturas previstas no parágrafo $3^{\circ}$ do artigo 10 da Lei $n^{\circ}$ 9.504/97, nos revela que existem maiorias políticas eventuais atualmente no Congresso Nacional dispostas a seguirem adiante com um projeto atentatório às normas de Direitos Humanos supracitadas e à Constituição de 1988.

A apresentação desse projeto, nesse contexto político peculiar, nos instiga a pensar no próprio papel e legitimidade do Supremo Tribunal Federal no controle de constitucionalidade preventivo, haja vista tratar-se de iniciativa claramente violadora dos direitos de minorias sub-representadas na esfera parlamentar (ELY, 2010); (ALMEIDA, SILVEIRA, FREITAS, 2016).

A proteção da participação política da mulher, que é um direito humano e fundamental, precisa ser fortalecido e não extinto, já que sequer logrou êxito em alcançar resultados mais satisfatórios em termos de igualdade de gênero na política. É preciso se avançar na proteção desse direito fundamental, para que não reste uma proteção deficiente, destacando-se que propostas de fortalecimento desse modelo de proteção jurídica existem (ALMEIDA, 2018) e, a cada eleição, vão sendo aprimoradas.

\subsubsection{A proibição do retrocesso político e democrático}

Como afirmado acima, maiorias políticas eventuais tentam revogar medidas afirmativas que ainda não atingiram resultados de inclusão favoráveis. Como apontado no capítulo um, a tendência contemporânea são os ordenamentos jurídicos adotarem normas que acelerem esse processo de paridade, garantindo, de fato, a presença de mulheres no Parlamento. O Direito realiza-se, aí, na sua função de instrumento de transformação social (FARIA, 1988). 
O relator da ADI $n^{\circ}$ 5617, Ministro Edson Fachin, iniciou o seu voto asseverando que é próprio do direito à igualdade a possibilidade de uma "desequiparação", desde que seja pontual e tenha por objetivo superar uma desigualdade histórica. Foi a primeira vez que o direito à participação política da mulher esteve no centro de um processo de deliberação da Suprema Corte brasileira (SUPREMO TRIBUNAL FEDERAL, online, 2018). A desigualdade não foi superada; o caminho ainda é longo, mas manter e aprimorar - necessariamente - o estatuto jurídico da mulher na política brasileira é fundamental.

A revogação das cotas de candidatura é um verdadeiro retrocesso no âmbito da proteção desse direito fundamental. A vedação ao retrocesso tem raízes históricas não só nos direitos sociais, mas também nos direitos a não discriminação ${ }^{7}$.

Pondera Macedo (2018, p. 351) ser umas das finalidades pretendidas pela vedação do retrocesso "evitar que o legislador ordinário venha a revogar integral ou parcialmente um ou mais diplomas legais (infraconstitucionais) que já se concretizaram a ponto de efetivar os direitos fundamentais".

Há farta literatura, já citada nos capítulos acima, que demonstram que sem essa reserva as mulheres não têm acesso à política formal por não encontrem espaço e apoio dos partidos políticos nesse sentido. Anota Miguel (2014, p. 305) que em uma “ordem política ideal, todos teriam igual potencial de influência nos processo decisórios e o sexo biológico, a cor da pele ou a orientação sexual em anda contribuiriam para predizer a chance de uma pessoa alcançar a posição de representante”. Contudo, não é o que a prática política nos revela, principalmente quando se compara a quantidade de mulheres presentes na política formal e na informal.

A prática política nos revela estar o acesso do poder político restrito ainda a certos grupos de modo que aquele que almeje disputar esses espaços enfrentará muitos obstáculos. Esses obstáculos advêm principalmente de uma situação de desigualdade presente nas estruturas sociais que acabam minando para as esferas políticas. A "baixa

\footnotetext{
7 Anota Vitor Gonçalves Macedo (2018, p.328) a respeito da vedação ao retrocesso: “Jeffries Jr. e Levinson (1998, p. 1215), por sua vez, analisam que o princípio ganhou especial destaque com o julgamento dos "race cases", casos que foram levados à Suprema Corte dos Estados Unidos da América (EUA) e que formaram a base para o estudo do princípio do não retrocesso no Direito Constitucional. Esses casos se tratavam de tentativas legislativas em estender proteções desagregadoras e discriminatórias como razoáveis e justas em questões de cunho escolar e imobiliário." Rev. de Teorias da Democracia e Direitos Políticos | e-ISSN: 2525-9660 | Goiânia| v. 5 | n. 1 | p. 82-103| 
representação das mulheres nos poderes governamentais indica uma forma de desigualdade incorporada ao sistema político" (BIROLI; MIGUEL, 2014, p. 104).

Logo, nessa perspectiva, que é a mesma de Canotilho (2003), é inconstitucional uma lei que extinga o espaço garantido e reservado para que as mulheres possam participar do processo eleitoral, vez que certamente tal revogação acarretará um prejuízo ao núcleo do direito fundamental da mulher de participar da política formal. A igualdade material, e seu conteúdo jurídico, previsto no art. $5^{\circ}$, I, da Constituição Federal será claramente violada.

\section{CONCLUSÕES FINAIS}

As cotas para mulheres na política existem em vários outros países, não só no Brasil, são constitucionais e amparadas em normas internacionais e visam alcançar um quadro mais equilibrado entre homens e mulheres na política, tendo em vista que as mulheres foram excluídas por séculos dos espaços formais de poder.

Os partidos são destinatários de comandos legais que estipulam deveres e lhe destinam recursos para formar e capacitar mulheres para o exercício da política formal. Ao deixarem de observar essas normas, criam um ciclo de autoexclusão da mulher na política, pois as vésperas do pleito "se socorrem" de candidaturas sem potencial político.

Clara é a responsabilidade partidária nesse quadro de desigualdade entres os sexos na política brasileira. Essa omissão pode tratar-se, inclusive, de mero jogo político e de interesses, vez que ao capacitarem as mulheres correm o risco de democratizar o poder partidário que hoje se concentra nas mãos de poucos grupos políticos. Assim, a falta dessa capacitação configura-se como estratégia de poder e a eficácia de uma norma não pode ser questionada sem que esse fator seja levado em consideração.

Esse fator reforça a necessidade da proteção da participação política da mulher através da adoção de novos mecanismos de inclusão de coloquem a mulher numa posição de real competividade e que sua inclusão não dependa da autonomia partidária. Os partidos políticos já revelaram, nesses últimos 20 (vinte) anos, não estarem dispostos a colaborar. 
O Projeto de Lei $\mathrm{n}^{\circ} 1.256 / 2019$ é inconstitucional por violar normas expressas contidas na Constituição de 1988 e por pretender enfraquecer a proteção jurídica da participação política da mulher. A simples revogação das cotas de candidaturas acarretaria um verdadeiro retrocesso de um direito que precisa, na contemporaneidade, ser fomentado e concretizado.

\section{REFERÊNCIAS}

ALMEIDA, Jéssica Teles de. A proteção jurídica da participação política da mulher:fundamentos teóricos, aspectos jurídicos e propostas normativas para o fortalecimento do modelo brasileiro. Dissertação (mestrado) - Universidade Federal do Ceará, Faculdade de Direito, Programa de Pós-Graduação em Direito, Fortaleza, 2018.

; MACHADO, Raquel Ramos Cavalcanti Machado. Abuso de poder político partidário e as fraudes às cotas de candidatura por gênero. In: Luiz Fux; Antônio Veloso Peleja Júnior; Frederico Franco Alvim; Julianna Santana Sesconetto. (Org.). Direito Eleitoral - Temas Relevantes. 1ed.Curitiba: Juruá, 2018a.

; MACHADO, Raquel Ramos Cavalcanti Machado. Os desafios das candidaturas femininas nas eleições de 2018. 2 de outubro de 2018b. Disponível em <https://www.conjur.com.br/2018-out-02/opiniao-desafios-candidaturas-femininaseleicoes-2018>. Acesso em 13 de fev. 2019.

; MACHADO, Raquel Cavalcanti Ramos. O Tribunal Superior Eleitoral na vanguarda da concretização do direito à participação das pessoas trans no processo eleitoral. Revista Populus, v. 1, p. 333-348, $2018 \mathrm{c}$.

.; SILVEIRA, Brunna Grasiella Matia; FREITAS, Raquel Coelho de. O papel do Amicus Curiae na democratização da defesa dos direitos das minorias no STF. In: CAMPOS, Juliane Cristine Diniz Campos (Coord.; MATOS, Rômulo Richard Sales; MELO, Silvana Paula Martins de (Org.) [et al] Democracia e Jurisdição Constitucional: estudos de interpretação da Constituição. $1^{\mathrm{a}}$ ed. Rio de Janeiro: Lumen Juris, 2016.

ARAÚJO, Clara. Potencialidades e limites da política de cotas no Brasil, p. 231/252. Revista de Estudos Feministas. Ano $n^{\circ}$ 09, $2^{\circ}$ Semestre, 2001.

Rotas de ingresso, trajetórias e acesso das mulheres ao legislativo- um estudo comparado entre Brasil e Argentina. Revista de Estudos Feministas, Florianópolis, v.18, p.567-584, n.2, maio/ago. 2010.

ARGENTINA oficializa paridade de gênero nas listas eleitorais. 15/12/2017. Disponível em: <https://noticias.uol.com.br/ultimas-noticias/efe/2017/12/15/argentinaRev. de Teorias da Democracia e Direitos Políticos | e-ISSN: 2525-9660 | Goiânia| v. 5 | n. 1 | p. 82-103| Jan/Jun. 2019 
oficializa-paridade-de-genero-nas-listas-eleitorais.htm>. Acesso em 25 de março de 2019.

ASSIS, Carolina de; FERRARI, Marília; LEÃO, Natalia. Câmara dos Deputados terá menos homens brancos e mais mulheres brancas, negras e $1^{\mathrm{a}}$ indígena em 2019. Gênero e número, Rio de Janeiro, 8 out. 2018. Disponível em:

<http://www.generonumero.media/camara-dos-deputados-tera-mais-mulheres-brancasnegras-e-indigena-e-menos-homens-brancos-em-2019/>. Acesso em: 19 fev. 2019.

AVELAR, Lúcia. Dos movimentos aos partidos: a sociedade organizada e a política formal. Revista Política e Sociedade, Florianópolis, v. 6, n. 11, p. 101-116, out. 2007. Disponível em: <https://periodicos.ufsc.br/index.php/politica/article/view/1310/1204>. Acesso em: 19 fev. 2019.

BERTHO, Helena. Mulheres laranja: ela não sabia que era candidata, mulheres são usadas para cumprir cota feminina nas eleições. The Intercept Brasil, 20 set. 2018. Disponível em: <https://theintercept.com/2018/09/19/partidos-mulheres-laranjas-cotaeleicoes/>. Acesso em: 20 fev. 2019.

BEAUVOIR, Simone. O Segundo Sexo. Rio de Janeiro: Nova Fronteira, 2000.

BIROLI, Flávia; MIGUEL, Luís Felipe. Feminismo e política: uma introdução. $1^{\mathrm{a}}$ ed. São Paulo: Boitempo, 2014.

BRASIL. Ministério das Mulheres, da Igualdade Racial e dos Direitos Humanos. Revista Observatório Brasil da Igualdade de Gênero. $1^{\text {a }}$ Impressão. Brasília: Secretaria de Políticas para as Mulheres, Dezembro, 2015, p. 12.

.VII Relatório Brasileiro da Convenção sobre a Eliminação de Todas as Formas de Discriminação contra a Mulher. Brasília, 2013. Disponível em < http://www.observatoriodegenero.gov.br/eixo/internacional/instancias-regionais/ocomite-cedaw-2013-comite-para-a-eliminacao-de-todas-as-formas-de-discriminacaocontra-a-mulher/cedaw-vii-relatorio-brasileiro.pdf>. Acesso em 05 de jan. 2019.

BUTLER, Judith. Problemas de Gênero: feminismo e subversão da identidade. Tradução Renato Aguiar. Rio de Janeiro: Civilização brasileira, 2003.

CANOTILHO, José Joaquim Gomes. Direito Constitucional e Teoria da Constituição. 7. ed. Coimbra: Almedina, 2003.

CONVENÇÃO Para Eliminar Todas as Formas de Discriminação Contra a Mulher - CEDAW (1979). Disponível em <http://www.pge.sp.gov.br/centrodeestudos/bibliotecavirtual/instrumentos/discrimulher. $\mathrm{htm}>$. Acesso em 12 de março de 2019

CONVENÇÃO sobre os Direitos Políticos da Mulher (1953). Disponível em http://www.direitoshumanos.usp.br/index.php/Direitos-da-Mulher/convencao-sobre-osdireitos-politicos-da-mulher.html. Acesso em 12 de dezembro de 2018. 
DAHL, Robert A. A democracia e seus críticos. São Paulo: Editora WMF Martins Fontes, 2012.

DIAS, Costa Joelson; QUINTELA, Débora Françolin. Participação política das mulheres no brasil: das cotas de candidatura à efetiva paridade na representação. Teorias da democracia e direitos políticos [Recurso eletrônico on-line] organização CONPEDI/UnB/UCB/IDP/UDF; Coordenadores: Armando Albuquerque de Oliveira, Rubens Beçak - Florianópolis: CONPEDI, 2016.

DWORKIN, Ronald. Levando os direitos a serio. São Paulo: Martins Fontes, 2010.

O direito da liberdade: a leitura moral da constituição norte-americana. São Paulo: Martins Fontes, 2006.

ELY, John Hart. Democracia e desconfiança. Tradução: Juliana Lemos. São Paulo: Martins Fontes, 2010.

FARIA, José Eduardo. Eficácia jurídica e violência simbólica: o direito como instrumento de transformação social. São Paulo: Editora Da Universidade De Sao Paulo. 1988.

FRASER, Nancy. Redistribuição, reconhecimento e participação: por uma concepção integrada de justiça. In: IKAWA, Daniela; PIOVESAN, Flávia; SARMENTO, Daniel. Igualdade, diferença e direitos humanos. Rio de Janeiro: Lumen Juris, 2010, p. 167189.

FUNDO Eleitoral e tempo de rádio e TV devem reservar o mínimo de $30 \%$ para candidaturas femininas, afirma TSE. 22/05/2018. Disponível em $<$ http://www.tse.jus.br/imprensa/noticias-tse/2018/Maio/fundo-eleitoral-e-tempo-deradio-e-tv-devem-reservar-o-minimo-de-30-para-candidaturas-femininas-afirma-tse > Acesso em 11 de jan. 2019.

HÁ diferenças entre transgêneros, travestis e transexuais?, 13/01/2017. Disponível em <https://br.mundopsicologos.com/artigos/ha-diferencas-entre-transgeneros-travestise-transexuais>. Acesso em 01/02/2019.

HTUN, Mala. A política de cotas na América Latina. Revista Estudos Feministas, Florianópolis, v.09, p.225-230, n.01, $2^{\circ}$ semestre 2001.

JUVÊNCIO, José Sérgio Martins. A relação entre candidaturas "laranjas" e a lei de cotas por gênero. Encontro Internacional Participação, Democracia e Políticas Públicas: aproximando agendas e agentes. 23 a 25 de abril de 2013, UNESP, Araraquara (SP), 2013.

KELSEN, Hans, Teoria pura do direito. Tradução João Baptista Machado. $6^{a}$ ed. São Paulo: Martins Fontes, 1998. 
LAFUENTE, Javier. A revolução incompleta da Bolívia. 11/10/14. Disponível em: <https://brasil.elpais.com/brasil/2014/10/11/internacional/1412983977_484279.html>. Acesso em 25 de março de 2019.

LOPES, Ana Maria D’Ávila Lopes; NÓBREGA, L. N. As ações afirmativas adotadas no Brasil e no Direito Comparado para fomentar a participação política das mulheres. Revista Nomos, Fortaleza, v. 31, n. 1, p. 11-30, jan./jun. 2011.

MARTINS, Eneida Valarini. A política de cotas e a representação feminina na Câmara dos Deputados. Monografia apresentada para aprovação no curso de Especialização em Instituições e Processos Políticos do Legislativo do programa de Pós-graduação do Cefor. Brasília: 2007.

MACEDO, Vitor Gonçalves. O incipiente princípio da proibição de retrocesso e sua função protetiva dos direitos fundamentais. Revista da Faculdade de Direito da UERJ, RJ, nº 34, dez. 2018.

MACHADO, Raquel Cavalcanti Ramos. Direito Eleitoral. São Paulo: Atlas, 2016.

MAZZA, Carlos. MPF irá instaurar procedimento para apurar suposta laranja. 13/02/2019. Disponível em <https://www.opovo.com.br/jornal/politica/2019/02/32421mpf-ira-instaurar-procedimento-para-apurar-suposta-laranja.html >. Acesso em $13 \mathrm{de}$ fev. 2019.

MAZOTTE; Natáli; ROSSI, Amanda. Partidos recorrem a candidatas "fantasmas" para preencher cota de 30\% para mulheres. Gênero e Número, Rio de Janeiro, 27 out. 2016. Disponível em: <http://www.generonumero.media/partidos-recorrem-candidatasfantasmas-para-preencher-cota-de-30-para-mulheres/>. Acesso em: 20 fev. 2019.

MIGUEL, Luís Felipe. Democracia e representação: territórios em disputa. São Paulo, Editora UNESP, 2014, p. 305.

MONTEIRO, Rosa. A Política de Quotas em Portugal: O papel dos partidos políticos e do feminismo de Estado. Revista Crítica de Ciências Sociais, 92, Março 2011: 31 -50, p. 31 .

MONTESANTI, Beatriz.Mulheres são $15 \%$ do novo Congresso, mas índice ainda é baixo.

08/08/2018.Disponívelem<https://noticias.uol.com.br/politica/eleicoes/2018/noticias/20 18/10/08/mulheres-sao-15-do-novo-congresso-mas-indice-ainda-e-baixo.htm>.Acesso. 13.02.2019.

NEVES, Marcelo. A constitucionalização simbólica. $1^{\text {a }}$ ed. São Paulo: Acadêmica, 1994.

ONU MULHERES. Marco normativo para consolidar a democracia paritária, 2014. Publicação da versão em português: 2018. Disponível em: 
$<$ http://www.onumulheres.org.br/wp-content/uploads/2018/06/Marco-NormativoDemocracia-Paritaria_FINAL.pdf.>. Acesso em 25 de março de 2019.

PROJETO que elimina cotas partidárias para mulheres tem voto contrário e críticas de senadoras. 20/03/2019. Disponível em $<$ https://www12.senado.leg.br/institucional/procuradoria/comum/projeto-que-eliminacotas-partidarias-para-mulheres-tem-voto-contrario-e-criticas-desenadoras?fbclid=IwAR3Ws6JwuTH_9qptDVokxIp6vDxBtIsbAfXB5sGv2j7eGHoAjT HuKwI-vvE>. Acesso em 02 de abril de 2019.

RAWLS, John. Uma teoria da justiça. São Paulo: Martins Fontes, 2000.

SÁNCHEZ MUÑOZ, Óscar. La igualdad de oportunidades en las competiciones electorales. Madrid: Centro de Estudios Políticos e Constitucionales, 2007.

SANTOS, Maria Helena Santos; SANTO, Ana Espírito-Santo. Para além dos Números: Transformações de Género associadas à Lei da Paridade. Journal of Studies on Citizenship and Sustainability. $\mathrm{n}^{\circ}$ 2, ano 2017.

SARMENTO, Daniel. Direito constitucional e igualdade étnico-racial. In FERREIRA, Renato (coord.). Ações afirmativas: a questão das cotas. s/e. Niterói, RJ: Impetus, 2011.

SCOTT, Joan. O enigma da igualdade. Revista Estudos Feministas, Santa Catarina, 2005.

SHAPIRO, Ian. Fundamentos morais da política. Tradução: Fernando Santos. São Paulo: Martins Fontes, 2006.

SUPREMO TRIBUNAL FEDERAL. STF decide que campanhas de candidatas terão mais recursos na eleição deste ano. 03/10/18. Disponível em <http://www.stf.jus.br/portal/cms/verNoticiaDetalhe.asp?idConteudo=391666>. Acesso em 25 de março de 2018.

SOUZA, Cristiane Aquino. Las cuotas electorales para la igualdad entre mujeres y hombres. 411 f. tese. (Doutorado em Direito) - Faculdad de Derecho, Departamento de Derecho Público y Filosofía Jurídica, Universidad Autónoma de Madrid, Madrid, 2011.

TRIBUNAL SUPERIOR ELEITORAL. Mulheres ainda são minoria de candidatas nas eleições brasileiras. 07/03/2018. Disponível em http://www.tse.jus.br/imprensa/noticias-tse/2018/Marco/mulheres-ainda-sao-minoriade-candidatas-nas-eleicoes-brasileiras. Acesso em 13 de fev. 2019.

VARIKAS, Eleni. Pensar o sexo e o gênero. Tradução: Paulo Sérgio de Souza. Campinas, São Paulo: Editora Unicamp, 2016.

Rev. de Teorias da Democracia e Direitos Políticos | e-ISSN: 2525-9660 | Goiânia| v. 5 | n. 1 | p. 82-103| Jan/Jun. 2019 
WALZER, Michael. Esferas da justiça: uma defesa do pluralismo e da igualdade.

São Paulo: Martins Fontes, 2003. 